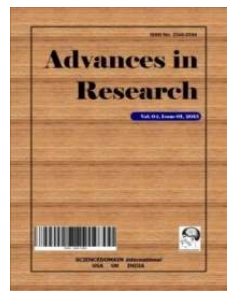

Advances in Research

8(2): 1-14, 2016, Article no.AIR.29264

ISSN: 2348-0394, NLM ID: 101666096

SCIENCEDOMAIN international

www.sciencedomain.org

\title{
Fixed Doses Combinations Acting on Cardiovascular System - Utilization and Generic Competition
}

\author{
Z. Mitkova ${ }^{1 *}$, M. Manova $^{1,2}$, S. Georgieva ${ }^{3,4}$ and G. Petrova ${ }^{1}$ \\ ${ }^{1}$ Faculty of Pharmacy, Medical University, Sofia, Bulgaria. \\ ${ }^{2}$ National Council of Pricing and Reimbursement, Sofia, Bulgaria. \\ ${ }^{3}$ Medical College, Medical University, Sofia, Bulgaria. \\ ${ }^{4}$ UMBAL Alexandrovska, Sofia, Bulgaria.
}

Authors' contributions

This work was carried out in collaboration with all authors. All authors read and approved the final manuscript.

Article Information

DOI: $10.9734 / \mathrm{AIR} / 2016 / 29264$

Editor(s):

(1) Sharon Lawn, Department of Psychiatry, Flinders Human Behaviour and Health Research Unit, Flinders University,

Australia.

Reviewers:

(1) S. I. R. Okoduwa, Ahmadu Bello University Zaria, Nigeria

(2) Anna Gumieniczek, Medical University of Lublin, Poland. Complete Peer review History: http://www.sciencedomain.org/review-history/16692

Original Research Article

Received $31^{\text {st }}$ August 2016

Accepted $19^{\text {th }}$ October 2016

Published $27^{\text {th }}$ October 2016

\section{ABSTRACT}

Aims: To analyze the impact of introduction of new fixed dose combinations (FDCs) in the Positive drug list on both the reference price and the utilization of reimbursed cardiovascular (CV) medicines. Study Design: It is a retrospective and observational analysis of the changes in reimbursed fixed dose combinations (FDCs) acting on cardiovascular system (CVS).

Place and Duration of Study: Medical University of Sofia, Faculty of Pharmacy for the period 2009-2013.

Methodology: On total 18 INNs (international nonproprietary name) in different combinations belonging to 6 anatomic therapeutic chemical (ATC) groups (ACE-inhibitor and diuretic, Caantagonists and ACE-inhibitors, sartan and diuretics, Ca-antagonist and statin, two diuretics, bblocker and diuretic); 60 dosage forms, and 104 trademarks were analyzed for changes in the prices and utilization after the inclusion in the Positive drug list (PDL).

Results: The number of the new generic medicines included in PDL is highest for the group of ACE 
-inhibitors and diuretics, angiotensin receptor blockers (AT receptor blockers, ARBs, sartans) and diuretics. Many new generic molecules as FDCs enter the PDL, thus leading to decrease in the reference price, because of generic competition. The decrease is significant in the new therapeutic groups. The changes in utilization calculated as defined daily dose (DDD)/1000 inhabitants/day show higher utilization in 2013 for the groups of ACE inhibitors and diuretics and AT receptor blockers and diuretics (Enalapril/ Hydrochlorthiazide (HCTZ), Perindopril/ Indapamide, Valsartan/HCTZ, Losartan/ HCTZ).

Conclusion: The study confirms that in Bulgaria the generic and therapeutic competition has increased during 2009-2013. It leads to significant price decrease and changes in the trends in utilization of the FDC in cardiology.

Keywords: Cardiovascular medicines; generic medicines; medicines prices; reference pricing; fixed doses combinations; DDD/1000 inh/ day.

\section{ABBREVIATIONS}

$\begin{array}{ll}A C E & : \text { Angiotensin-converting enzyme } \\ A H T & : \text { Antihypertensive therapy } \\ A P I & : \text { Active pharmaceutical ingredient } \\ A R B & : \text { Angiotensin receptor blockers, sartans, } \\ A T & : \text { Receptor blockers } \\ A T C & : \text { Anatomic therapeutic chemical } \\ B D A & : \text { Bulgarian Drug Agency } \\ B P & : \text { Blood pressure } \\ C C B & : \text { Calcium channel blockers } \\ G P S & : \text { General Practitioners } \\ C T & : \text { Combination therapy } \\ C V & : \text { Cardiovascular } \\ C V D & : \text { Cardiovascular diseases } \\ C V S & : \text { Cardiovascular system } \\ D D D & : \text { Defined daily dose } \\ D R I & : \text { Direct renin inhibitors } \\ E S A C & : \text { European Surveillance of Antimicrobial } \\ & \text { Consumption } \\ F C & : \text { Free combinations } \\ F D C & : \text { Fixed dose combinations } \\ H C T Z & : \text { Hydrochlorthiazide } \\ I N N & : \text { International nonproprietary name } \\ P D L & : \text { Positive Drug List } \\ R A A S & : \text { Renin-angiotensin-aldosterone system } \\ W H O & : \text { World Health Organization } \\ & \end{array}$

\section{INTRODUCTION}

The cardiovascular diseases (CVD) are major cause of the disease burden (illness and death) in Europe (23\% of all diseases). Of the total cost of CVD in the EU, around $57 \%$ is due to health care costs, $21 \%$ due to productivity losses and $22 \%$ due to informal care of people with CVD. [1].

Study in Bulgaria shows that cardiovascular risk is high in a large proportion of Bulgarian urban population, especially in men aged over 65 . A representative sample of Bulgarian urban population ( $n=3810$, response rate $68.3 \%$ ) from five Bulgarian cities was included in a crosssectional observation study performed in the period 2005-2007. Nearly a quarter of the sample had a total cardiovascular risk of over $10 \%$ (SCORE $\geq 10 \%$ ), whereas $10.1 \%$ of the sample had excessively high cardiovascular risk (SCORE $\geq 15 \%$ ). In the 65-75 age group, the prevalence of men with excessively high risk was $46.6 \%$, compared with $6.0 \%$ in women [2].

As the current guidelines recommend [3] patients in advanced hypertension stages should be treated with two or more antihypertensive drugs. Combination therapy is used in approximately $75 \%$ [4] of patients with hypertension. Combination therapy reduce the blood pressure (BP) and exhibit excellent tolerability [4].

The concept of combination therapy is based on treatment with two, or more active pharmaceutical ingredients (API). They could be administered in a fixed-dose combination (FDC) or separately. It is proved that the combination therapy in the majority of patients with hypertension is effective in reaching target blood pressure $[5,6]$. The studies confirm that it leads also to cost savings and better compliance with the prescribed therapy $[7,8]$.

Treatment with combination therapy offers some advantages compared to monotherapy. The combination therapy sometimes can influence the compensatory mechanisms induced by one of the drugs and prevents the adverse reactions. Some combinations of antihypertensive agents could exhibit additive or synergic effect. Additive decrease of the blood pressure is documented with the combination of an ACE-Inhibitor, ARB, or DRI (direct renin inhibitors) with a calcium channel blockers (CCB) [9]. A recent study has shown that ACE-Inhibitors are more efficacious 
than ARBs in decreasing peripheral edema associated with CCB therapy [10]. Meta-analysis of 42 trials $(10,968$ participants) quantifies the incremental effect of combining drugs from any classes (thiazides, beta-blockers, angiotensinconverting enzyme inhibitors, and calcium channel blockers) over 1 drug alone and the results from combining drugs with doubling dose. The extra blood pressure reduction from combining of drugs from 2 different classes is approximately 5 times greater than doubling the dose of the drug used as monotherapy [11].

The high-risk patients with hypertension and accompanying diseases (like diabetes) can be treated with combining two drugs (ACE inhibitor, ARB and diuretic or ACE inhibitor and Calcium channel blocker) to achieve better result in control of blood pressure with a low rate of side effects. The compliance of patients will be improved and cardiovascular morbidity and mortality, costs and patient adverse events will be decreased [12]. The studies for combination therapy showed improved rates of blood pressure control and less time to achieve the target blood pressure $[1,13,14]$, lower incidence results from the adverse effects, fewer patient visits, and reduced cost to the health care system [14].

Study on the management of hypertension based on data from 770 geographically diverse primary care cities (77\% GPs, $23 \%$ cardiologists) found that monotherapy was started in 1550 (26.4\%) and combination therapy (CT) in 4328 (73.6\%) patients. $1003(17.1 \%)$ patients were on fixed dose combination (FDC) alone, and 3325 $(56.6 \%)$ on free combinations (FC). The most frequently used FDC and FC were angiotensin receptor blockers and diuretics (54\%, resp. $28 \%$ ). Diuretics, b-blockers, angiotensin receptor blockers were more frequently used in females than in males - $22 \%, 47 \%, 22 \%$, resp. $19 \%, 42 \%$, $19 \%$. ACE-inhibitors are the more frequently used in males than females - $29 \%$ vs $26 \%$, showing that $\mathrm{CV}$ medicines utilization could vary depending on the patient's gender. In Bulgaria CT, especially FC was preferred as initial hypertension therapy than monotherapy. Monotherapy was prescribed more frequently in low/moderate risk, CT in high/very high risk. Bblockers were used as initial therapy unjustified frequently [15].

Other study compares hypertension therapy in Bulgaria and Serbia. The results show that patients in Bulgaria are often treated with monotherapy (61\% in Bulgaria vs $6 \%$ in Serbia), as well as those with complications $(66 \%$ vs $0 \%$ Serbia). In both countries the first choice of therapy are the ACE inhibitors $37.01 \%$ in Serbia and $41 \%$ in Bulgaria), followed by the calcium antagonists, beta-blockers, and diuretics [16].

Fixed dose combinations as initial therapy may lead to improved compliance of patients and reduced cardiovascular morbidity and mortality [17]. In the latest years many new FDCs, especially in cardiology, were introduced on the market.

The objective of this study is to analyze the impact of introduction of new fixed dose combinations (FDCs) in the positive drug lists on the reference price and utilization of reimbursed cardiovascular (CV) medicines during 2009-2013 years.

\section{MATERIALS AND METHODS}

It is a retrospective and observational analysis for the period 2009-2013 performed in Bulgaria. Changes in reference price per defined daily dose (DDD) were observed. The reference price is the lowest retail market price per DDD of FDCs acting on cardiovascular system. All prices are expressed in national currency at the exchange rate 1 Euro $=1.958 \mathrm{BGN}$.

Systematically was reviewed the Positive drug list (PDL), which include all reimbursed medicines. The observed combinations are from the therapeutic groups of ACE - inhibitors and diuretics, ACE-inhibitors and $\mathrm{Ca}$-antagonists, statin and diuretic, b-blocker and diuretic, two diuretics, sartans and diuretics. All of the FDCs were analyzed for the following changes - new active pharmaceutical ingredients (API) inclusion, new generic products, new concentrations and dosage forms entering the PDL.

The utilization is calculated in DDD/1000 inh/day according to established World Health Organization (WHO) formulas:

$\mathrm{DDD} / 1000 \mathrm{inh} /$ day $=(($ Sales data in $\mathrm{mg} /$ $\mathrm{DDD}) /\left(\mathrm{N}\right.$ inhabitans $\left.{ }^{*} 365\right) 2 \times 1000$

Sales data are provided by BDA (Bulgarian Drug Agency) and DDD of the products were derived from $\mathrm{WHO}$ website. We use formula approved by WHO for DDD/1000 inh/day and the methodology accepted by ESAC (European Surveillance of Antimicrobial Consumption) for 
calculation of the utilization. Only the DDD of the active substance leading in the combination (according to ATC-code) was considered.

18 FDCs included in PDL presented in 60 dosage forms out of 104 trademarks were analyzed for the changes in reference price and utilization.

T-test was applied for statistical significance of the changes based on the average value of reference price per DDD and DDD/1000 inh/day.

\section{RESULTS AND DISCUSSION}

Combinations of ACE-inhibitor and diuretic are the largest group with the highest number of dosage forms and generics included into the PDL. For the combination Enalapril/ Hydrochlorothiazide (HCTZ) we observed decrease in the reference price for all of dosage forms (Fig. 2). The utilization of combinations increased from $18.72 \mathrm{DDD} / 1000 \mathrm{inh} /$ day to 18.76 $\mathrm{DDD} / 1000 \mathrm{inh} /$ day and remain very high in comparison with the other ACE inhibitors/ diuretics combinations (Fig.1).

For the combination, Lisinopril/HCTZ new trademarks were included in PDL and the reference price decreased in 2012. The utilization has increased significantly from 0.61 to 3.07 DDD/1000 inh/day. The new generics included in PDL encourage generic competition. For the combination Perindopril/ Indapamide the utilization increases significantly from 0,73 to $6,95 \mathrm{DDD} / 1000$ inh/day. 4 new dosage forms were included in PDL in 2012 and the reference price also decreased significantly (Table 1, Fig. 2).

Table 1. Number of dosage forms and trade names of FDCs of ACE-inhibitor and diuretic

\begin{tabular}{|c|c|c|c|c|c|c|c|c|c|c|c|}
\hline \multirow[t]{2}{*}{ INN } & \multirow[t]{2}{*}{ API, mg } & \multicolumn{5}{|c|}{ Number of dosage forms } & \multicolumn{5}{|c|}{ Number of trade names } \\
\hline & & 2009 & 2010 & 2011 & 2012 & 2013 & 2009 & 2010 & 2011 & 2012 & 2013 \\
\hline \multirow{3}{*}{ 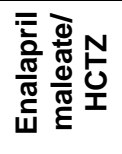 } & $20 / 12,5$ & 4 & 4 & 4 & 4 & 4 & 4 & 4 & 4 & 4 & 4 \\
\hline & $10 / 12,5$ & 1 & 2 & 2 & 2 & 2 & & & & & \\
\hline & $10 / 25$ & 1 & 2 & 2 & 2 & 2 & & & & & \\
\hline \multirow{2}{*}{ 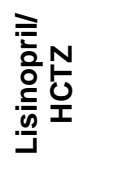 } & $20 / 12,5$ & 1 & 1 & 1 & 1 & 3 & 1 & 1 & 1 & 1 & 3 \\
\hline & $10 / 12,5$ & 1 & 1 & 1 & 1 & 3 & & & & & \\
\hline \multirow{5}{*}{ 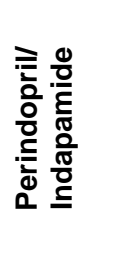 } & $5 / 1,25$ & 1 & 1 & 1 & 1 & 2 & 1 & 1 & 1 & 4 & 6 \\
\hline & $2.5 / 0,625$ & 1 & 1 & 1 & 1 & 1 & & & & & \\
\hline & 102,5 & - & - & - & 2 & 2 & & & & & \\
\hline & $4 / 1,25$ & - & - & - & 1 & 5 & & & & & \\
\hline & $\begin{array}{l}8 / 2,5 \\
2 / 0,625\end{array}$ & - & $\begin{array}{l}- \\
-\end{array}$ & - & $\begin{array}{l}1 \\
2\end{array}$ & $\begin{array}{l}1 \\
3\end{array}$ & & & & & \\
\hline \multirow{3}{*}{ 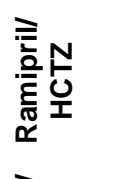 } & $\begin{array}{l}2,5 \\
/ 12,5\end{array}$ & 4 & 4 & 4 & 1 & 3 & 5 & 5 & 5 & 3 & 5 \\
\hline & $5 / 25$ & 4 & 4 & 4 & 3 & 4 & & & & & \\
\hline & $\begin{array}{l}10 / 25 \\
10 / 125\end{array}$ & - & - & - & - & $\begin{array}{l}1 \\
1\end{array}$ & & & & & \\
\hline \multirow{3}{*}{ 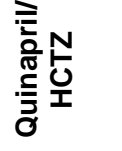 } & $10 / 12,5$ & 1 & 1 & 1 & 3 & 4 & 1 & 1 & 1 & 3 & 4 \\
\hline & $20 / 12,5$ & 1 & 1 & 1 & 3 & 4 & & & & & \\
\hline & $20 / 25$ & - & - & - & 1 & 2 & & & & & \\
\hline 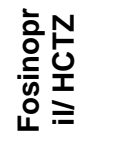 & $20 / 12,5$ & 1 & 1 & 1 & 2 & 2 & 1 & 1 & 1 & 2 & 2 \\
\hline 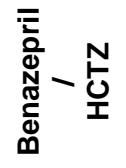 & $20 / 25$ & - & - & - & 2 & 2 & - & - & - & 2 & 2 \\
\hline
\end{tabular}




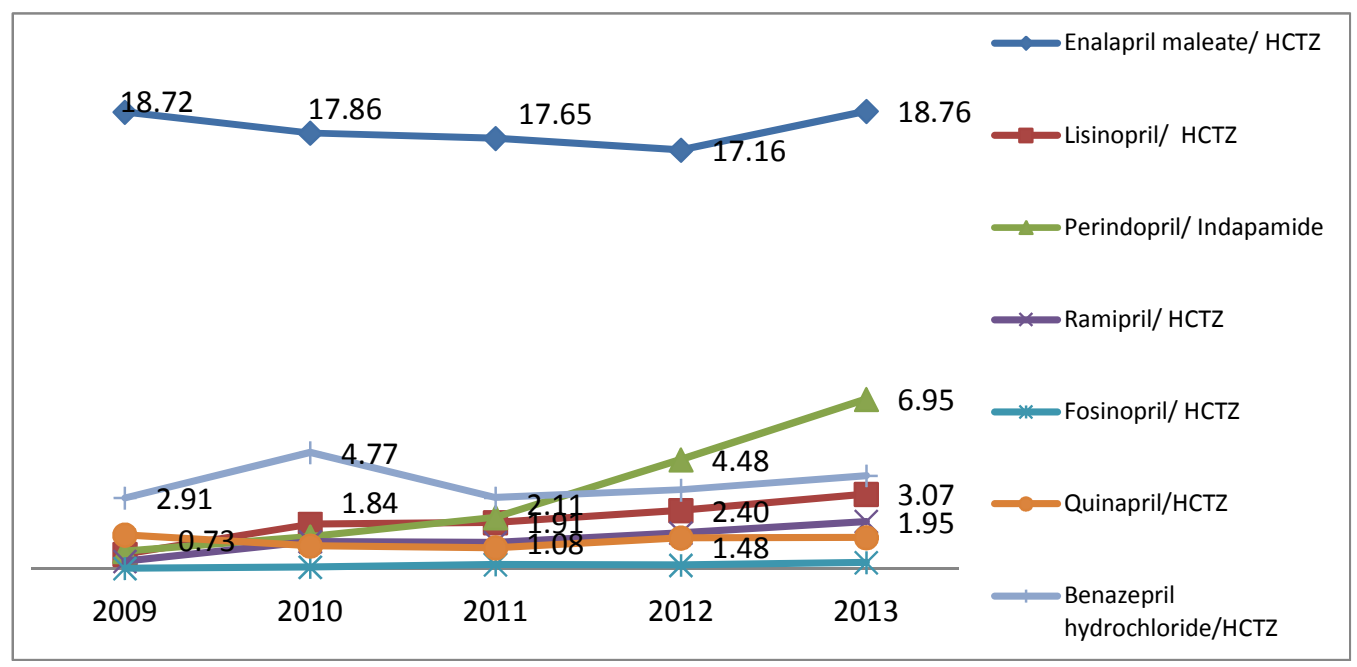

Fig. 1. Changes in DDD/1000 inh/day for FDCs of ACE-inhibitors and diuretic

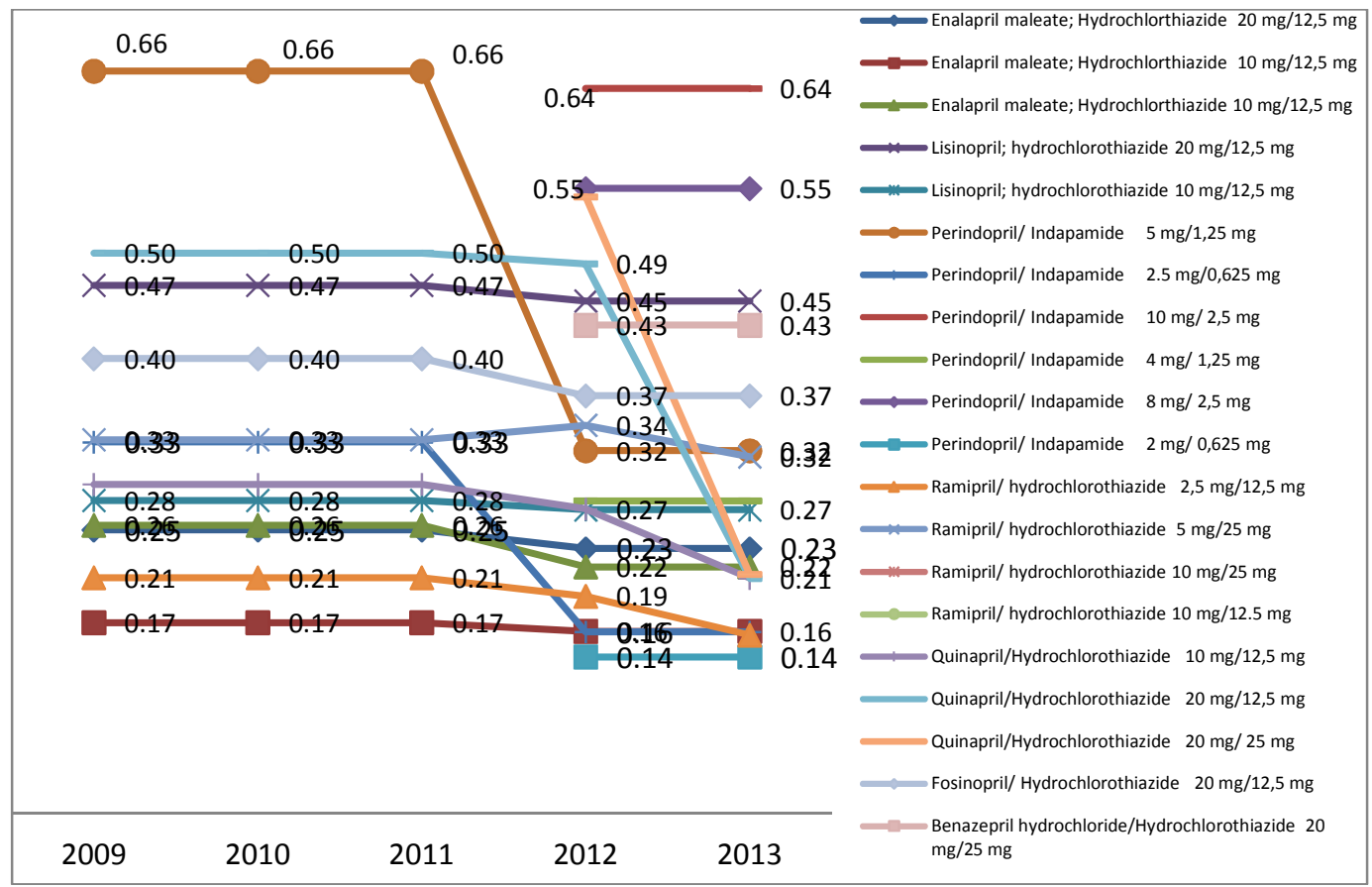

Fig. 2. Changes in reference price per DDD for the FDCs of ACE-inhibitors and diuretic

For the other combinations similar changes in utilization and reference price per DDD were observed. New dosage forms included in PDL within the period let to increased generic and therapeutic competition. Exception is the FDC Benazepril/HCTZ 20/25 mg for which there is no new products and no changes in reference price. The utilization increased insignificantly.

FDCs of ACE- inhibitor and calcium channel blocker diminish numerous adverse event of
CCB as for example the legs edema. The combination of calcium-channel blockers and ACE inhibitors could have a synergistic effect. The results show that the combination of nitrendipine and captopril appears to be a very effective and well-tolerated for the treatment of mild to moderate primary hypertension $[18,19,20,21]$. We observed the changes in reference price and the utilization for 3 FDCs of ACE inhibitors and $\mathrm{Ca}$ channel blockers included in PDL (Table 2). The increase in utilization of 
FDCs of Lisinopril/ Amlodipine and Perindopril/ Amlodipine is significant $(0.55 \mathrm{DDD} / 1000 \mathrm{inh} /$ day to $3.37 \mathrm{DDD} / 1000 \mathrm{inh} /$ day and 0.64 to 5.40 $\mathrm{DDD} / 1000 \mathrm{inh} /$ day respectively (Fig. 3 ). The reference price per DDD decreases for all FDCs and it is the most obviously for the combinations of Perindopril/ Amlodipine. The high number of new trademarks increases competition, resulting in a decrease of the reference price from one side and to increased consumption on the other side.

Table 2. Number of dosage forms and trade names of FDCs of Ca-antagonists/ACE-inhibitors

\begin{tabular}{|c|c|c|c|c|c|c|c|c|c|c|c|}
\hline \multirow{2}{*}{ INN } & \multirow{2}{*}{$\begin{array}{l}\text { API, } \\
\text { mg }\end{array}$} & \multicolumn{5}{|c|}{ Number of dosage forms } & \multicolumn{5}{|c|}{ Number of trade names } \\
\hline & & 2009 & 2010 & 2011 & 2012 & 2013 & 2009 & 2010 & 2011 & 2012 & 2013 \\
\hline \multirow{3}{*}{ 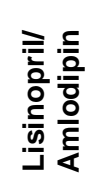 } & $10 / 5$ & 1 & 1 & 1 & 1 & 1 & 1 & 1 & 1 & 1 & 1 \\
\hline & $20 / 10$ & - & - & - & 1 & 1 & & & & & \\
\hline & $20 / 5$ & - & - & - & - & 1 & & & & & \\
\hline 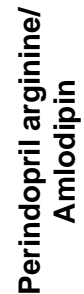 & $\begin{array}{l}5 / 10 \\
10 / 5 \\
10 / 10 \\
5 / 5 \\
4 / 5 \\
4 / 10 \\
8 / 5 \\
8 / 10\end{array}$ & $\begin{array}{l}1 \\
1 \\
1 \\
1 \\
- \\
- \\
- \\
-\end{array}$ & $\begin{array}{l}1 \\
1 \\
1 \\
1 \\
- \\
- \\
- \\
-\end{array}$ & $\begin{array}{l}1 \\
1 \\
1 \\
1 \\
- \\
- \\
- \\
-\end{array}$ & $\begin{array}{l}1 \\
1 \\
1 \\
1 \\
- \\
- \\
- \\
-\end{array}$ & $\begin{array}{l}1 \\
1 \\
1 \\
1 \\
1 \\
1 \\
1 \\
1\end{array}$ & 1 & 1 & 1 & 1 & 2 \\
\hline 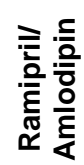 & $\begin{array}{l}5 / 5 \\
10 / 5 \\
10 / 10\end{array}$ & $\begin{array}{l}- \\
-\end{array}$ & $\begin{array}{l}- \\
-\end{array}$ & $\begin{array}{l}- \\
-\end{array}$ & $\begin{array}{l}- \\
-\end{array}$ & $\begin{array}{l}2 \\
1 \\
1\end{array}$ & - & - & - & - & 2 \\
\hline
\end{tabular}

Table 3. Number of dosage forms and trade names of FDCs of sartan and diuretics

\begin{tabular}{|c|c|c|c|c|c|c|c|c|c|c|c|}
\hline \multirow[t]{2}{*}{ INN } & \multirow[t]{2}{*}{ API, mg } & \multicolumn{5}{|c|}{ Number of dosage forms } & \multicolumn{5}{|c|}{ Number of trade names } \\
\hline & & 2009 & 2010 & 2011 & 2012 & 2013 & 2009 & 2010 & 2011 & 2012 & 2013 \\
\hline \multirow{3}{*}{ 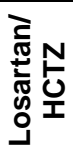 } & $50 / 12.5$ & 2 & 2 & 2 & 5 & 6 & \multirow[t]{3}{*}{2} & \multirow[t]{3}{*}{2} & \multirow[t]{3}{*}{2} & \multirow[t]{3}{*}{5} & \multirow[t]{3}{*}{6} \\
\hline & $100 / 25$ & 1 & 1 & 1 & 1 & 1 & & & & & \\
\hline & $100 / 12,5$ & - & - & - & 1 & 1 & & & & & \\
\hline \multirow{5}{*}{ 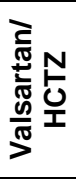 } & $80 / 12,5$ & 1 & 2 & 2 & 1 & 3 & \multirow[t]{5}{*}{3} & \multirow[t]{5}{*}{4} & \multirow[t]{5}{*}{4} & \multirow[t]{5}{*}{7} & \multirow[t]{5}{*}{11} \\
\hline & $160 / 12,5$ & 3 & 4 & 4 & 6 & 9 & & & & & \\
\hline & $160 / 25$ & 3 & 4 & 4 & 5 & 8 & & & & & \\
\hline & $320 / 25$ & - & - & - & 1 & 1 & & & & & \\
\hline & $320 / 12,5$ & - & - & - & 1 & 1 & & & & & \\
\hline \multirow{2}{*}{ 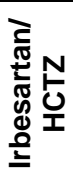 } & $150 / 12,5$ & - & - & - & 1 & 3 & \multirow[t]{2}{*}{-} & \multirow[t]{2}{*}{-} & \multirow[t]{2}{*}{-} & \multirow[t]{2}{*}{1} & \multirow[t]{2}{*}{3} \\
\hline & $300 / 12,5$ & - & - & - & 1 & 3 & & & & & \\
\hline \multirow{4}{*}{ 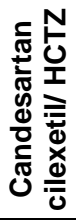 } & $8 / 12,5$ & - & - & - & 3 & 4 & \multirow[t]{4}{*}{-} & \multirow[t]{4}{*}{-} & \multirow[t]{4}{*}{1} & \multirow[t]{4}{*}{4} & \multirow[t]{4}{*}{6} \\
\hline & $16 / 12,5$ & - & - & 1 & 4 & 6 & & & & & \\
\hline & $32 / 12.5$ & - & - & - & - & 2 & & & & & \\
\hline & $32 / 25$ & - & - & - & - & 1 & & & & & \\
\hline \multirow{2}{*}{ 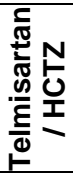 } & 80 / 25 & 1 & 1 & 1 & 1 & 3 & \multirow[t]{2}{*}{1} & \multirow[t]{2}{*}{1} & \multirow[t]{2}{*}{1} & \multirow[t]{2}{*}{1} & \multirow[t]{2}{*}{3} \\
\hline & $80 / 12,5$ & 1 & 1 & 1 & 1 & 3 & & & & & \\
\hline
\end{tabular}




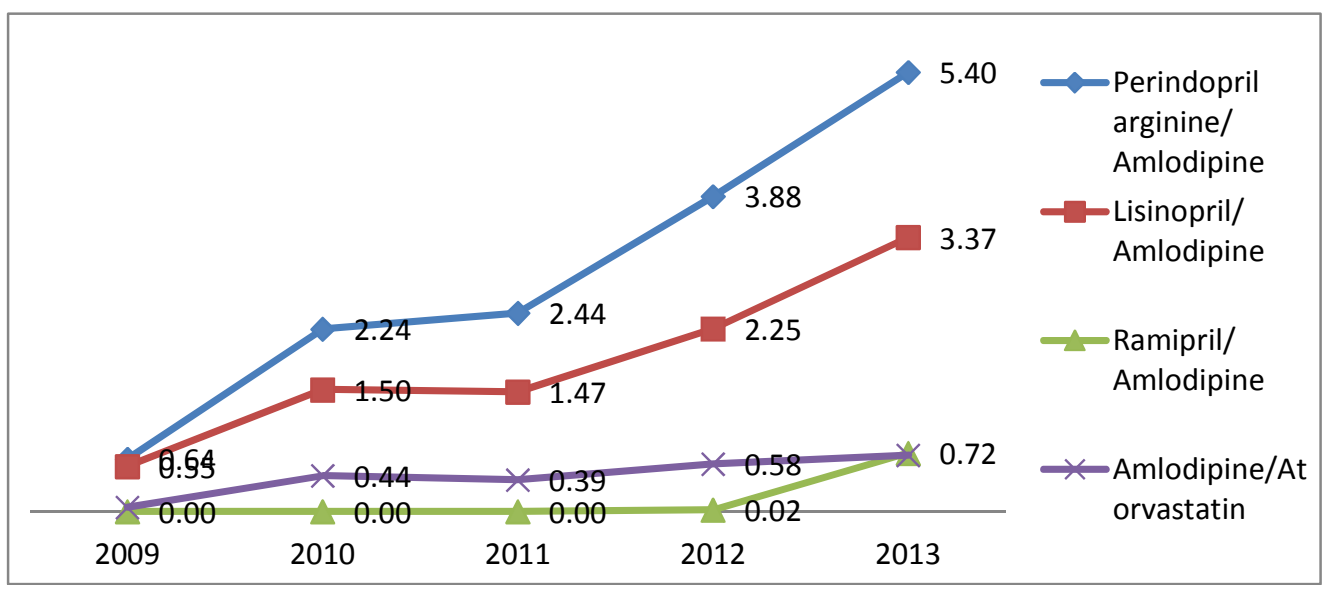

Fig. 3. Changes in DDD/1000 inh/day for group of ACE-inhibitors and Ca-antagonists

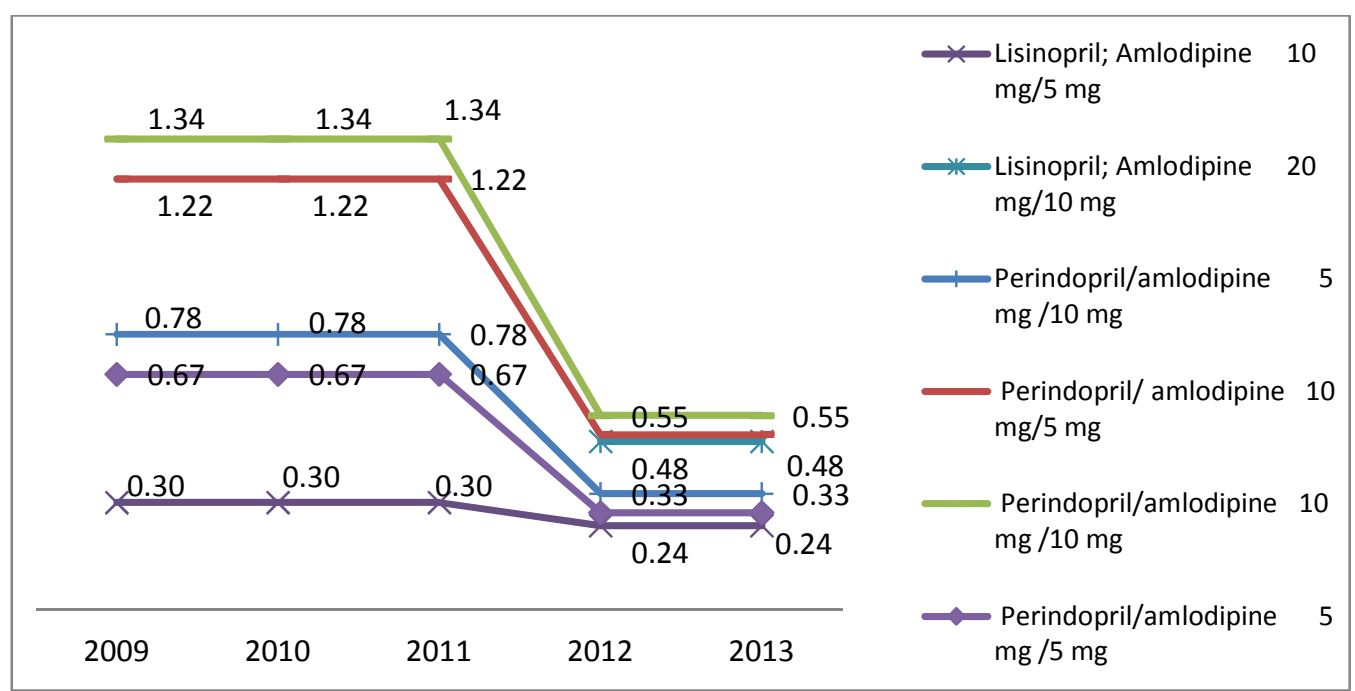

Fig. 4. Changes in reference price per DDD for the FDCs of ACE-inhibitor and Ca-antagonist

The reference price per DDD decreases from 1,222 to 0,497 for the combination $10 \mathrm{mg}$ perindopril/5 $\mathrm{mg}$ amlodipine and from 1,33600 to 0,550 for the combination $10 \mathrm{mg}$ perindopril/10mg amlodipine between 2009-2013 years (Fig. 4).

FDC of renin-angiotensin-aldosterone system (RAAS) inhibitor and a diuretic in low-doses shows higher reduction of blood pressure and response to therapy than both APIs administered separately. It also compensates the increased plasma renin activity provoked by the diuretic $[22,23,24,25]$. During the observed period FDCs of sartan and diuretic performed steady increase in their dosage forms, trademarks and new international non-proprietary name (INN). For FDC of Valsartan/HCTZ 8 new trademarks were included in PDL, and for combination,
Candesartan/HCTZ 5 new trademarks were included (Table 3 ). On total 43 new generic medicines were included in the group during 2009 - 2013. The results show that it is one of the most dynamic groups. The higher number of new generic forms leads to decrease of the reference price per DDD and increase of the utilization (Fig. 5; Fig. 6). The most significant decrease in reference price is for Telmisartan/HCTZ $80 \mathrm{mg} / 25 \mathrm{mg}$ (from 2,208 to 0.581), Telmisartan/ HCTZ $80 \mathrm{mg} / 12,5 \mathrm{mg}$ (from 1,253 to 0.495 ), Valsartan/ HCTZ $160 \mathrm{mg} / 25 \mathrm{mg}$ (from 1,077to 0.512). The changes in utilization of Valsartan/ HCTZ are significant - from 2,25 to $27.69 \mathrm{DDD} / 1000 \mathrm{inh} /$ day.

The reference price and utilization are significantly impacted from the high number of new products included in PDL within 
observed period and for all products it is decreasing.

For the FDC of Amlodipine and Atorvastatin after the introduction of new dosage forms in PDL the reference price per DDD decreased in 2012 and 2013 while the utilization has increased (Table $4)$.

The combination of beta blockers and diuretics blunt the increase in the plasma renin level that is induced by diuretics, and decreases water retention caused by beta blockers [26]. Studies showed that monotherapy with either agent was more effective than placebo. If the combination therapy is used, the beneficial effect would have been greater than that of either agent used alone [27]. In the group of b-blocker and diuretic, we observed the changes in reference price per DDD for the combinations of bisoprolol/ HCTZ. The utilization of combinations has increased insignificantly within observed period from 0.76 to $1.1 \mathrm{DDD} / 1000 \mathrm{inh} /$ day regardless the changes in reference price (Fig. 7; Fig. 8). In 2012 new dosage form and trademark were included in PDL (Table 5). In the same year reference price per DDD decreases for all combinations of bisoprolol/HCTZ (Fig. 8).

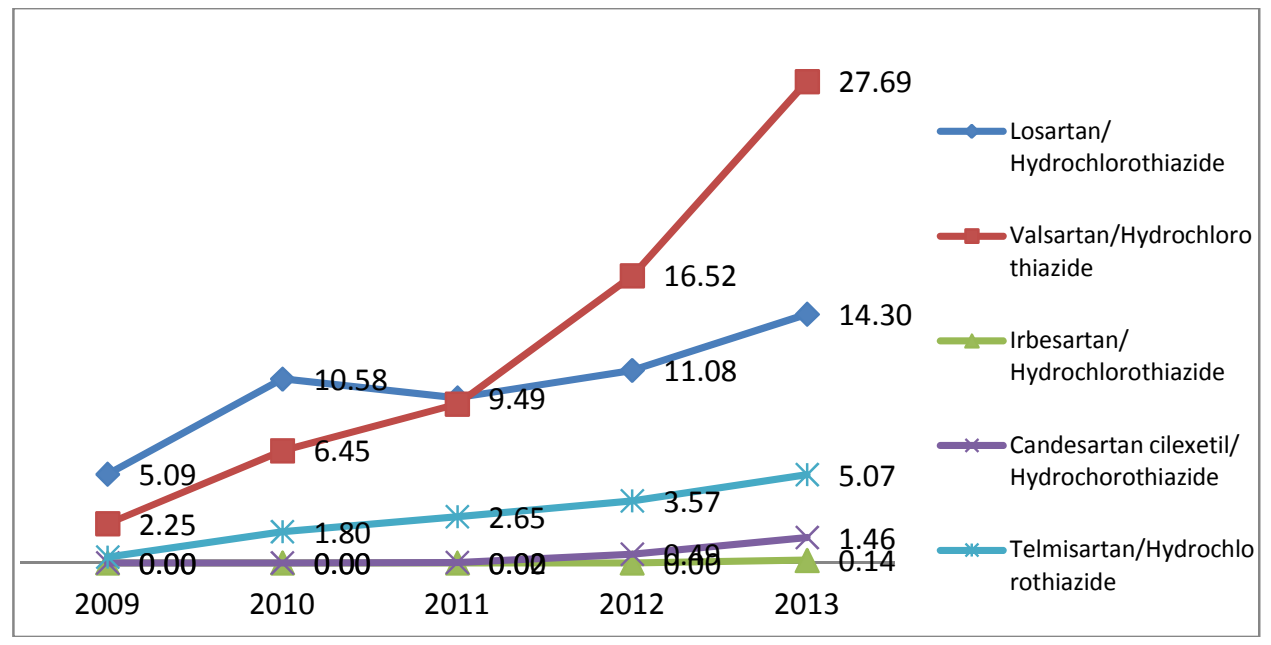

Fig. 5. Changes in utilization in DDD/1000 inh/day of FDCs of sartans and diuretics

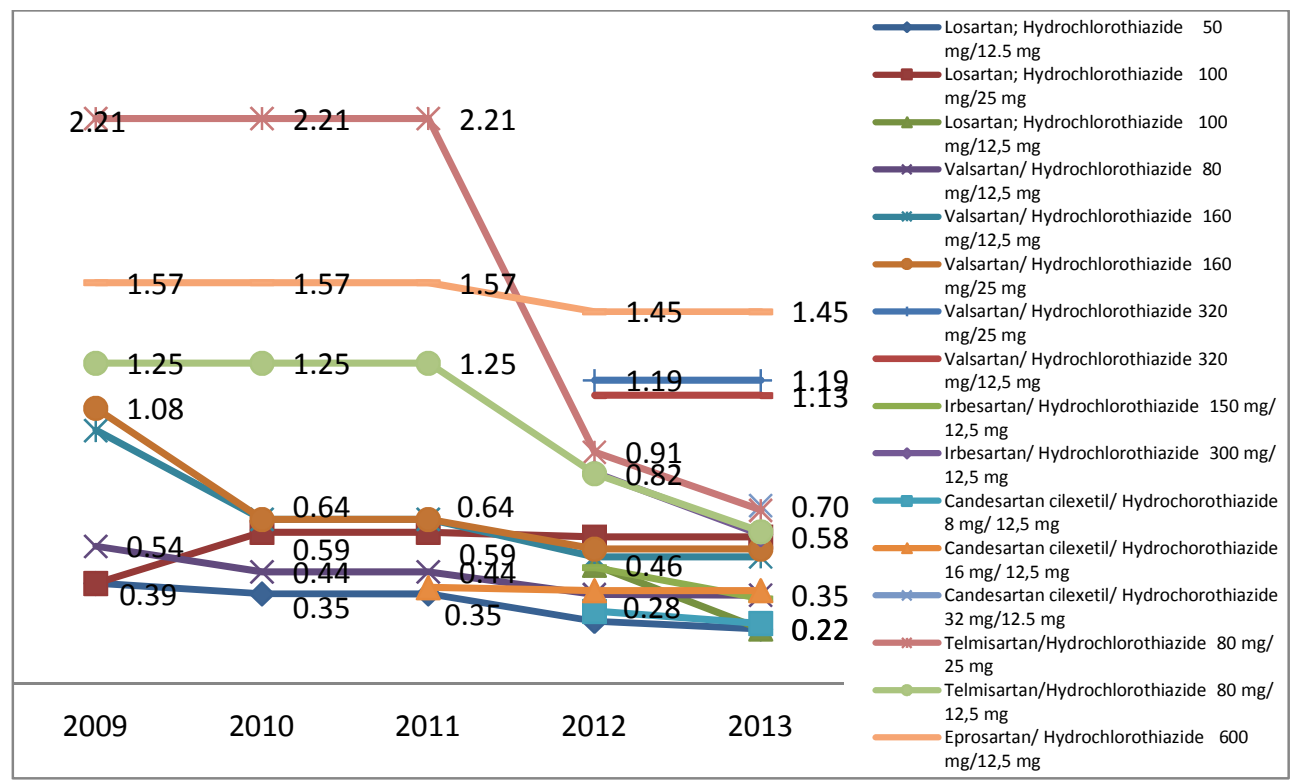

Fig. 6. Changes in reference price per DDD of FDCs of sartans and diuretics 
Mitkova et al.; AIR, 8(2): 1-14, 2016; Article no.AIR.29264

Table 4. Number of dosage forms and tradenames, reference price per DDD, DDD/1000 inh/day (BGN) for the group of Ca-antagonist and statin

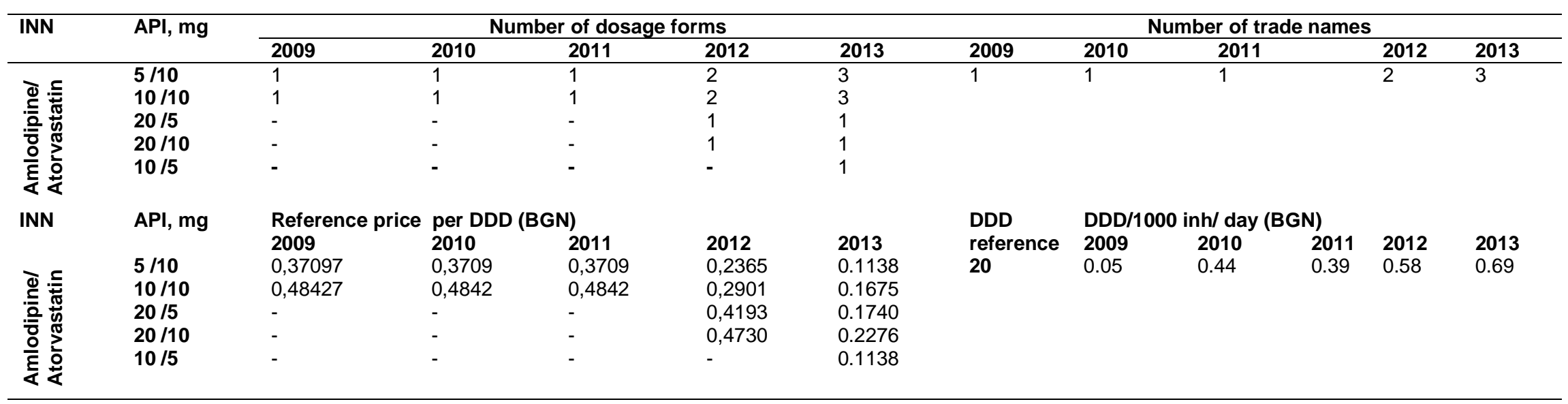


Table 5. Number of dosage forms and tradenames for the FDCs of $\beta$-blocker and diuretic

\begin{tabular}{|c|c|c|c|c|c|c|c|c|c|c|c|}
\hline \multirow[t]{2}{*}{ INN } & \multirow[t]{2}{*}{ API, mg } & \multicolumn{5}{|c|}{ Number of dosage forms } & \multicolumn{5}{|c|}{ Number of trade names } \\
\hline & & 2009 & 2010 & 2011 & 2012 & 2013 & 2009 & 2010 & 2011 & 2012 & 2013 \\
\hline \multirow{4}{*}{ 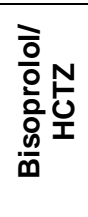 } & $5 / 12,5 \mathrm{mg}$ & 1 & 1 & 1 & 2 & 2 & 2 & 2 & 2 & 3 & 3 \\
\hline & $2.5 / 6.25 \mathrm{mg}$ & 1 & 1 & 1 & 1 & 1 & & & & & \\
\hline & $5 / 6.25 \mathrm{mg}$ & 1 & 1 & 1 & 1 & 1 & & & & & \\
\hline & $10 / 6.25 \mathrm{mg}$ & 1 & 1 & 1 & 1 & 1 & & & & & \\
\hline
\end{tabular}

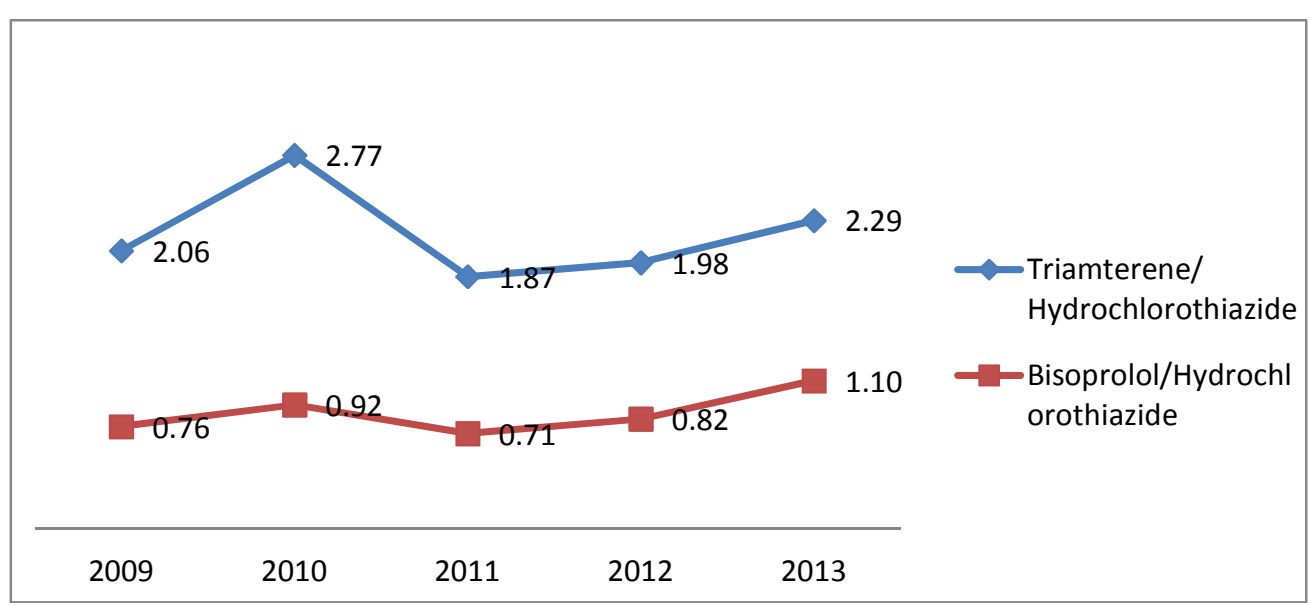

Fig. 7. Changes in utilization in DDD/1000 inh/day for FDC of $\beta$-blockers/ diuretic and combination of two diuretics

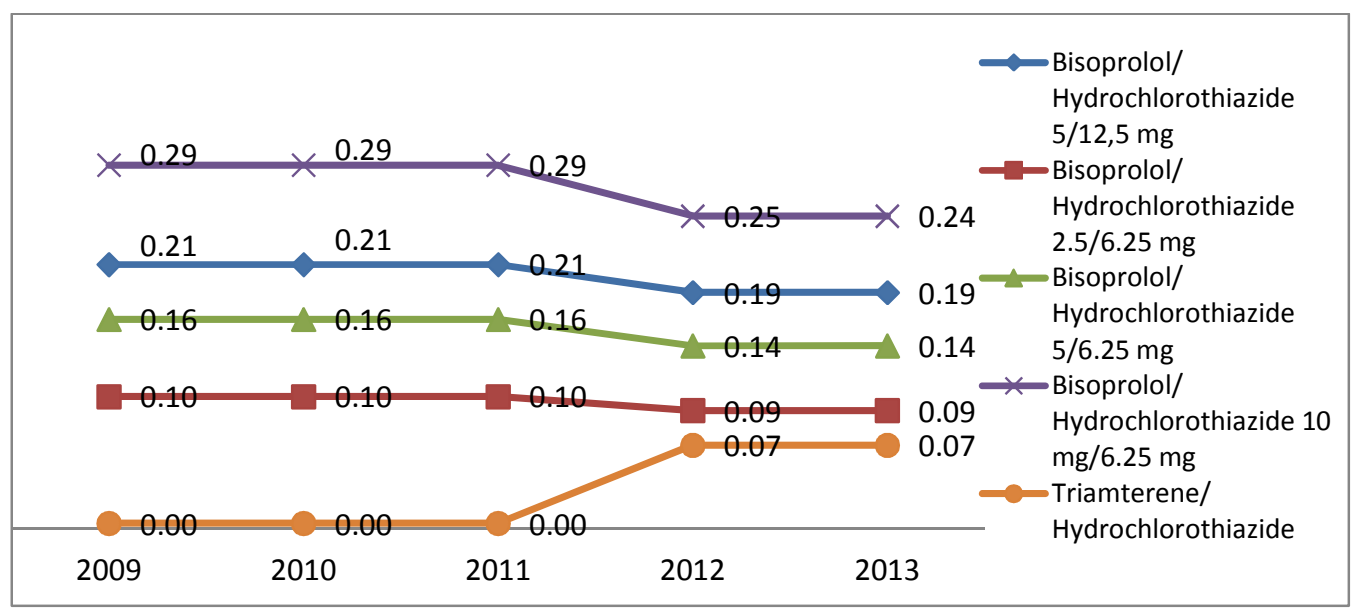

Fig. 8. Changes in reference price for FDC of $\beta$-blockers/diuretic and two diuretics

The combination of two diuretics Triamterene and Hydrochlorothiazide has been studied also. There are no included new dosage forms and trademarks within observed period. DDD/1000 inh/day has increased slightly. The variations in reference price per DDD are not so significant between 2009-2013 years.
There are various changes in utilization and reference price per DDD in the cardiology medicines. The relationship between the cost per DDD and the utilized DDD/1000 inh/day provides information of how the utilization of expensive medicines compares with that of less expensive. 
Other studies have shown that FDC of ACE inhibitor-diuretic achieves therapeutic control and improve the blood pressure in approximately 80 percent of patients $[28,29]$. The results were proved in multicenter, double-blind, placebocontrolled trial. The lower doses of hydrochlorothiazide both alone or in combination with lisinopril were equipotent with higher doses and were free of metabolic side effects [28]. Antihypertensive drug combinations containing ACE- inhibitor and lower dose of hydrochlorothiazide are preferred in Bulgaria as the first choice for monotherapy [16]. Our study confirms that the combination therapy with ACEinhibitors/diuretics and statins/diuretic were most preferred. Within the observed period, the use in $\mathrm{DDD} / 1000$ inh/day has increased in all therapeutic groups, but the greatest increases were marked for the FDC of Valsartan/HCTZ, Losartan/ HCTZ and Perindopril/ Indapamide.

The results from the other study [15] shows that in Bulgaria FDCs were underused compared with the monotherapy. Monotherapy was prescribed more frequently in low/ moderate risk patients. In patients with high/very high risk, the CT was used more often. Our study confirms that during the latest years the utilization of FDCs has increased which is a result from the high number of reimbursed medicines included in PDL and the increasing competition. We proved also that there is an inverse relationship between the price per DDD and utilization of medicines in Bulgaria. In a study from South Africa the same results are reported for antipsychotic, antidepressant, hypnotic and anxiolytic drugs [30].

The reference price has decreased significantly in 2012 and many new medicines are included in PDL. In this period, legislative changes were introduced and National Council on Prices and Reimbursement of Medicinal Products was created. The reference price has decreased significantly mainly for the newer dynamic groups with many new dosage forms and new trademarks included in PDL [31].

The results from T-test shows that there are many statistically significant changes in the utilization and reference prices. In the analysis were compared DDD/1000 inh/day and reference price per DDD for every group between 2009 2013. The highest change in utilization is found for the group of ACE - inhibitors and $\mathrm{Ca}$ antagonists, $p=0.113$. The highest change in reference price is found for the group of ACE inhibitors and $\mathrm{Ca}$ antagonists, $\mathrm{p}=0.167$ and $\mathrm{b}$ - blocker/ diuretic (we observe combination bisoprolol/HCTZ only), $p=0.113$. Similar are the results for the variations of the reference price. The reference price reduces significantly for some products, but within the group it is not statistically significant.

Other factors that influence the medicines utilization could be changes in price, generic competitors used as alternatives in clinical practice, preferences and prescribing habits of the physicians. Many studies confirm that utilization of FDC improves compliance of the patients and decreases the cost of therapy for the cardiovascular diseases and their consequences in case of bad control $[32,33,34]$.

The patients treated with FDCs had better persistence $(42.5 \%$ higher; $P<0.002)$ and compliance $(22.1 \%$ higher; $P<0.001)$, compared with the patients who were switched from FDCs. The higher compliance rate $(22.1 \%)$ is associated with lower costs for hypertensionrelated health care $(P<0.001)$ and reduction in hypertension-related expenditures as a whole. [35].

The National consensus for antihypertensive medicines utilization recommends combinations with proven effectiveness and tolerability as are the:

- Thiazide or loop diuretics and $\beta$-blockers;

- Thiazide or loop diuretics and ACE inhibitors or ARB

- Beta blockers and a receptor blockers

- Beta blockers and Ca channel blockers

- ACE inhibitors and Ca channel blockers [12].

The current analysis shows that all mentioned therapeutic groups noted increasing utilization in the latest years. This means that medicines utilization follows the scientific evidences and the latest pharmacotherapeutic recommendations.

This is the first Bulgarian study comparing the utilization in $\mathrm{DDD} / 1000 \mathrm{inh} /$ day, reference price per DDD, and the number of the approved trademarks and generic medicines of FDCs during 2009 - 2013. Limitation of the study is the calculation of utilization when only DDD of the leading substance is used [36].

The high number of the new generic products as INNs and trademarks included during 2009-2013 suggests that there are effective measures for 
generic competition and therapeutic competition stimulation in the country. When the reference price per DDD is decreasing the utilization as $\mathrm{DDD} / 1000 \mathrm{inh} /$ day is increasing, especially for the new and dynamic therapeutic groups. The therapeutic and generic competition is one of the leading factors influencing the changes in price and utilization of CV medicines FDCs.

\section{CONCLUSION}

The study confirms that in Bulgaria the utilization of newer cardiovascular fixed dose combinations has increased due to decreasing reference price per DDD and the growing number of the approved new generic medicines and new dosage forms. This is an indicator that treatment is based on the recent standards and guidelines. It also confirms that the generic entrance let to competitive pharmaceutical market.

\section{COMPETING INTERESTS}

Authors have declared that no competing interests exist

\section{REFERENCES}

1. Allender $S$, Scarborough $P$, Peto $V$, Rayner M, Leal J, Luengo-Fernandez R, Gray A. European cardiovascular disease statistics. European Heart Network, Brussels, England; 2008.

Available:http://hdl.handle.net/10536/DRO/ DU:30020501

2. Dyakova M, Shipkovenska E, Dyakov $P$, Dimitrov $P$, Torbova S. Cardiovascular risk assessment of Bulgarian urban population: Crosssectional study. Croat Med J. 2008;49:783-91.

DOI: $10.3325 / \mathrm{cmj} .2008 .49 .783$

3. Mancia G, DeBacker G, Dominiczak A, et al. The task force for the management of arterial hypertension of the European Society of Hypertension (ESH) and of the European Society of Cardiology (ESC): 2007 Guidelines for the Management of Arterial Hypertension. J Hypertens. 2007;25:1105-1187.

4. Gradman A. Strategies for combination therapy in hypertension. Curr Opin Nephrol Hypertens. 2012;21(5):486-491.

Available:http://www.medscape.com

5. Chobanian AV, Bakris GL, Black HR, Cushman WC, Green LA, Izzo JL Jr et al. Seventh Report of the Joint National
Committee on prevention, detection, evaluation, and treatment of high blood pressure. Hypertension. 2003;42(6):12061252. Epub 2003 Dec 1.

DOI:10.1161/01.HYP.0000107251.49515.C 2

6. Tedesco MA, Natale F, Calabro R. Effects of monotherapy and combination therapy on blood pressure control and target organ damage: A randomized prospective intervention study in a large population of hypertensive patients. J Clin Hypertens. 2006;8(9):634-641.

7. Giles TD. Rationale for combination therapy as initial treatment for hypertension. J Clin Hypertens (Greenwich). 2003;5(4)(suppl 3):4-11.

8. Epstein M, Bakris G. Newer approaches to antihypertensive therapy. Use of fixeddose combination therapy. Arch Intern Med. 1996;156(17):1969-1978.

9. Sever PS, Messerli FH. Hypertension management 2011: Optimal combination therapy. Eur Heart J. 2011;32(20):2499506. Epub 2011 Jun 22.

DOI: 10.1093/eurheartj/ehr177

10. Makani H, Bangalore S, Romero J, WeverPinzon O, Messerli FH. Effect of reninangiotensin-system blockade on calcium channel blockers associated peripheral edema. Am J Med. 2011;124:128-135.

11. Wald DS, Law M, Morris JK, Bestwick JP, Wald NJ. Combination therapy versus monotherapy in reducing blood pressure: Meta-analysis on 11,000 participants from 42 trials. Am J Med. 2009;122(3):290-300. DOI: 10.1016/j.amjmed.2008.09.038 Available:http://www.ncbi.nlm.nih.gov/pub med/19272490

12. Torbova S, Gocheva N, Sirakova V, Tarnovska R, Donova T, Vlahov V. Consensus on monotherapy and combination therapy of patients with arterial hypertension in Bulgaria. Sofia; 2005.

Available:http://dl.cardiobg.com/index.php/ eurukovodstva/521

13. Bakris GL, Weir MR, Black HR. Improving blood pressure control rates: is there more we can do? J Clin Hypertens (Greenwich). 2007;9(2):134-142.

14. Taylor AA. Combination drug treatment of hypertension: Have we come full circle? Curr Cardiol Rep. 2004;6(6):421-6.

15. Raev D, Barkalova D. Initial antihypertensive therapy in Bulgaria. A national prospective, observational study 
(BP-initial therapy - BG study). Journal of Hypertension. 2015;16:33-35.

16. Ivanova A, Lakic D, Andric V, Petrova G, Cost of outpatient hypertension pharmacotherapy: Comparative study between Bulgaria and Serbia. Pharmacy Practice. 2009;7(2):108-112.

17. Kober S. Cardiovascular therapy. Evidence based medicine-questions and answers. 2nd ed. Medpharm-Scientific Publishers, Stuttgart, Germany. 2002;11.

18. Hansson L, Himmelmann A. Calcium antagonists in antihypertensive therapy. $J$ Cardiovasc Pharmacol. 1991;18(suppl 10): S76-S80.

19. Gennari C, Nami R, Pavese G, Gragnani S, Bianchini C, Buracchi P. Calciumchannel blockade (nitrendipine) in combination with ACE inhibition (captopril) in the treatment of mild to moderate hypertension. Cardiovasc Drugs Ther. 1989;3(suppl 1):319-25.

20. Sierra A. Mitigation of calcium channel blocker related oedema in hypertension by antagonists of the renin-angiotensin system. Journal of Human Hypertension. 2009;23:503-511.

21. Sica D. Calcium channel blocker-related periperal edema: Can it be resolved? J Clin Hypertens (Greenwich). 2003;5(4): 291-294,297.

22. Bains J, Smith WB. Valsartan plus hydrochlorothiazide: A review of its use since its introduction. Expert Opin Pharmacother. 2011;12(12):1975-84. Epub 2011 Jul 6.

DOI: $10.1517 / 14656566.2011 .587124$

Available:http://www.ncbi.nlm.nih.gov/pub $\mathrm{med} / 21728903$

23. Edes I. Multicentre Study Group. Combination therapy with candesartan cilexetil $32 \mathrm{mg}$ and hydrochlorothiazide $25 \mathrm{mg}$ provides the full additive antihypertensive effect of the components: A randomized, double-blind, parallel-group study in primary care. Clin Drug Investig. 2009;29(5):293-304.

DOI: $\quad 10.2165 / 00044011-200929050-$ 00002

Available:http://www.ncbi.nlm.nih.gov/pub $\mathrm{med} / 19366271$

24. Derosa G, Ferrari I, Cicero AF. Irbesartan and hydrochlorothiazide association in the treatment of hypertension. Curr Vasc Pharmacol. 2009;7(2):120-36.

Available:http://www.ncbi.nlm.nih.gov/pub med/19355995
25. Rosenstock J, Rossi L, Lin CS, Mac Neil $D$, Osbakken M. The effects of irbesartan added to hydrochlorothiazide for the treatment of hypertension in patients nonresponsive to hydrochlorothiazide alone. $\mathrm{J}$ Clin Pharm Ther. 1998;23(6):433-40.

26. Neutel JM, Black HR, Weber MA. Combination therapy with diuretics: An evolution of understanding. Am $\mathrm{J}$ Med. 1996;101:61S-70S.

27. Frishman WH, Bryzinski BS, Coulson LR, De Quattro VL, Vlachakis ND, Mroczek $W J$, et al. A multifactorial trial design to assess combination therapy in hypertension. Treatment with bisoprolol and hydrochlorothiazide. Arch Intern Med. 1994;154:1461-8.

28. Chrysant SG. Antihypertensive effectiveness of low-dose Lisinopril hydrochlorothiazide combination. A large multicenter study. LisinoprilHydrochlorothiazide Group. Arch Intern Med. 1994;154:737-43.

29. Townsend RR, Holland OB. Combination of converting enzyme inhibitor with diuretic for the treatment of hypertension. Arch Intern Med. 1990;150:1175-83.

30. Truter I, Wiseman IC, Kotze TJ. The defined daily dose as a measure of drug consumption in South Africa. A preliminary study. S Afr Med J. 1996;86(6):675-9.

31. Annex № 1 to PDL, National Council on Prices and Reimbursement of Medicinal Products.

Available:http://www.ncpr.bg/en/registers/a nnex-\%E2\%84\%96-1-to-pdl

32. Erdine S. How do compliance, convenience, and tolerability affect blood pressure goal rates? Am J Cardiovasc Drugs. 2012;12:295.

DOI: 10.1007/BF03261838

Available:http://link.springer.com/article/10. 1007/BF03261838

33. Benford M, Milligan G, Pike J, Anderson P, Piercy J, Fermer S. Fixed-dose combination antidiabetic therapy: Realworld factors associated with prescribing choices and relationship with patient satisfaction and compliance. Adv Therapy. 2012;29:26.

DOI: $10.1007 / \mathrm{s} 12325-011-0096-\mathrm{z}$

Available:http://link.springer.com/article/10. 1007/s12325-011-0096-z

34. Pan F, Chernew, ME, Fendrick AM. Impact of fixed-dose combination drugs on 
adherence to prescription medications. $J$ Gen Intern Med. 2008;23(5):611614.

DOI: 10.1007/s11606-008-0544-x611

Available:http://link.springer.com/article/10. 1007/s11606-008-0544-x

35. Hess G, Hill J, Lau H, Dastani H, Chaudhari P. Medication utilization patterns and hypertension related expenditures among patients who were switched from fixed-dose to freecombination antihypertensive therapy. PT. 2008;33(11):652-66.

36. Guidelines for ATC classification and DDD assignment. 16th edition. WHO Collaborating Centre for Drug Statistics Methodology. Norwegian Institute of Public Health; 2013.

(c) 2016 Mitkova et al.; This is an Open Access article distributed under the terms of the Creative Commons Attribution License (http://creativecommons.org/licenses/by/4.0), which permits unrestricted use, distribution, and reproduction in any medium, provided the original work is properly cited.

Peer-review history:

The peer review history for this paper can be accessed here: http://sciencedomain.org/review-history/16692 